\title{
Changes in safety of Working Conditions as a Result of Introducing 5S Practices
}

\author{
Anna CIERNIAK-EMERYCH and Robert GOLEJ
}

Wrocław University of Economics, Wrocław, Poland

Correspondence should be addressed to: Robert GOLEJ; robert.golej@ue.wroc.pl

Received date: 14 November 2019; Accepted date: 4 February 2020; Published date: 6 July 2020

Academic Editor: Rafal Kozlowski

Copyright (C) 2020. Anna CIERNIAK-EMERYCH and Robert GOLEJ.Distributed under Creative Commons Attribution 4.0 International CC-BY 4.0

\begin{abstract}
Changes occurring in the economic and social systems, often referred to as Industry 4.0, relate to the employment structure in the economy. More employees will find jobs in the services sector and creative industries. These changes create new threats. The non-physical working conditions and the mental health of the employees are becoming increasingly important. The purpose of the research results presented in the article is to identify and learn about the relationship between the implementation of $5 \mathrm{~S}$ practices and the safety of working conditions. This will allow a better understanding of the phenomena accompanying the implementation of 5S practices and their impact on employees' health. This makes it necessary for researchers to identify the goals set before implementing $5 \mathrm{~S}$ practices in the light of the working conditions and to analyze their actual and potential impact on employees' health. The authors conducted bibliographic studies, in-depth interviews with employees and managers of the company, and analyzed documentation on the implementation of 5S. The study used the case study method. The authors, as a result of the research, identified practices used in companies when implementing the $5 \mathrm{~S}$ principles and they found that the implementations did not take into account the context of the working conditions and the impact of the implementations on the employees' physical and mental health. They also determined that the main goal of the implementations was to maximize work efficiency. Where the working conditions improved, it occurred as an unintended effect. The authors have identified areas that can improve the mental well-being and health of employees when implementing and using $5 \mathrm{~S}$ practices.
\end{abstract}

Keywords: 5S, lean management, safe and healthy working conditions.

Cite this Article as: Anna CIERNIAK-EMERYCH and Robert GOLEJ (2020)," Changes in safety of Working Conditions as a Result of Introducing 5S Practices", IBIMA Business Review, Vol. 2020 (2020), Article ID 141027, DOI: $10.5171 / 2020.141027$ 


\section{Introduction}

Changes in the requirements with regard to the working conditions result from many variables. One of them is the selfawareness of employees and their organizations in terms of the necessity to use basic solutions ensuring occupational health and safety, and complex personnel policies ensuring fairness of working conditions, often developed at a philosophical-ethical and economic level. Therefore, the problems of working conditions for employees do not only concern the enterprise which employs the employees, but they are also part of the socio-economic governance that ensures its sustainability.

Bearing in mind the above approach, the scale and weight of the problems of working conditions should be emphasized. The greater the scale of globalization and concentration understood in many different ways, the greater the importance of the problem. This paper attempts to present the problems arising at the interface between lean manufacturing and working conditions.

The problem discussed in the study concerns the attempt to answer the question whether the widely understood working conditions were taken into account when implementing solutions for $\mathrm{LM}$ in the selected manufacturing companies in Lower Silesia, which implemented at least LM elements. Were the effects on the mental and physical health of the workers before and after the implementation of lean methods studied?. The article is based on broader research conducted by the authors. Research also refers to the relationship between the implementation of LM and the safety of working conditions and creative activities.

The paper used the findings presented by previous researchers (desk research) in order to define the importance and scope of the problems discussed. The next part was based on the empirical material related to lean management (LM) implementations collected in three manufacturing companies in Lower Silesia.

As a result of the analysis, conclusions were drawn regarding the consideration of conscious shaping of working conditions in the design and implementation of LM solutions in the light of employees' health in the physical and mental sense. The implementation of LM in these enterprises involved the implementation of the $5 \mathrm{~S}$ method, which is widely considered to be particularly related to the shaping and even improvement of working conditions.

\section{Theoretical background}

\section{Working Conditions and Associated Safety in the Work Process}

Working conditions are most often considered as all the factors occurring in the work process that affect the human situation in the enterprise in which this work process is carried out; inside and outside.

In literature, these conditions are usually divided into two main groups of elements, i.e. physical and non-physical components, within which individual items are additionally distinguished. The physical components include physical, material, chemical and biological elements, such as workstations, room equipment, lighting, microclimate, noise, etc. A. CierniakEmerych (2005) mentioned that the nonphysical components mean working time, interpersonal relations, and social and living activities. The importance of working conditions is also reflected in the fact that the European Foundation for the Improvement of Living and Working Conditions decided to clarify this category (2019). The foundation defines working conditions as a set of factors that relate to the working environment and the aspects of the employees' employment. This includes the following issues:

- Type of work including its organization;

- Training, development of skills and competences and employability (neologism); 
- Health, safety and well-being;

- Working time and work-life balance.

In the analysis of the literature, it can also be noted that the definition of working conditions does not change drastically over the last dozen years or even more than that.

However, the literature sometimes separates the concept of safety from working conditions. Most often, when considering working conditions, researchers also point to work safety. If the emphasis is on safety, the risks mostly concern the physical health. If the focus is placed on the working conditions, then the subject matter is much broader. However, the authors of this article are with the opinion that security should be seen more broadly. In their opinion, the term safe working conditions is worth using, which should be considered as the lack of unacceptable circumstances of work performance, posing a risk of injury that can affect the health and life of the employee, assuming that the sources of these damages should be seen in the influence of material and non-material elements of working conditions.

The literature also uses the term work environment and the quality of the work environment, as if separating working conditions into the sphere of physical impact and the quality of the working environment as a set of factors shaping mental health. This approach can be seen for example in Cropanzano's article (2005). According to many authors, e.g. Krot and Lewicka (2015), the quality of the working environment consists of many elements, including: the level of trust in the organization, fairness in the organization, feeling of support from the organization and support from superiors. However, as usual, the reality is much more complex as it turns out that research demonstrated the psychosomatic character of the human health. Mental health affects the physical health and vice versa. The first fundamental field of interest for researchers that examines the working conditions was the analysis of the effect of working conditions on the physical health (accidents and occupational diseases). Next, the researchers focused more on the effect of working conditions on health in a broader sense, not only in physical, but also in mental terms. In literature, however, these terms are often used interchangeably and defined for research purposes. Nowadays, working conditions should be identified with the broadly understood working environment.

At the end of the 1970s, Karasek (1979) pointed to two basic groups of working conditions that determine mental health; the intensity of work and the complexity of work. The many researchers enumerated the characteristics of work that can increase psychological tension defined by Sperandio (1980) as 'a term associated with an affective rather than cognitive area, and that has all the negative effects, and all the pollution associated with professional activity'. Karasek and Theorell (1979, 1991) also developed an index of the mental tension that evaluates mental demand, decision width and social support. The basic idea behind this index is that work complexity and social support counterbalance the negative effects of excessive psychological demand. This has been demonstrated in many empirical studies, e.g. Stock et al. (2006) and Lucifora and Cottini (2013). Many researchers try to measure a wide spectrum of measuring working conditions, e.g. Coupaud (2017). Sirven, N., Cardebat. J. M. and Coupaud, they also address these issues in the light of the concept of corporate social responsibility (CSR).

Research can therefore be done to identify factors that shape the safety of working conditions or, more anthropologically, their changes, and the strength of their effect on the physical and mental health, well-being, productivity, creativity, etc. This article focuses on the relationships between the safety of working conditions and the implementation of $5 \mathrm{~S}$ practices, which are one of the tools of the lean management concept. In particular, it is about considering the awareness of employers and employees related to the benefits and limitations in the area of shaping this 
security in connection with the implementation of $5 \mathrm{~S}$ practices

In Poland, as Walentynowicz (2013) claims, the lean management concept is usually described as "lean production", "lean manufacturing", "lean management" or "lean organization".

Acting according to the 'lean' concept means the most efficient use of the available materials and company resources to achieve the best possible results. This mainly means a series of activities aimed at eliminating waste in the broad sense of the term, not only that occurring during the manufacturing process, but also from the entire area around it, including the network of logistic connections.

In the book by Kornicki and Kubik (2008), in Japan, three types of waste have been enumerated:

- muda (futility) - when production exceeds demand,

- mura (unevenness) - sometimes production exceeds demand, sometimes it does not,

- muri (unreasonableness) - when demand exceeds production.

This method identifies seven basic types of waste: overproduction, excess inventory, improper transport, defects, unnecessary processing, unnecessary downtime and excessive traffic.

The literature indicates the entire range of LM tools from basic TPM, through SMED, JiT and 5S. It is worth mentioning that the $5 \mathrm{~S}$ system is considered to be particularly related to shaping and even improving working conditions. Gapp et al. (2008) prove that the 5S system (practice) is considered to be a tool used to support solving problems related to work organizations. Some researchers, such as Karaszewski (2009), indicate that this helps not only enhance the work organization but also improve the conditions and safety at work. Therefore, attempts are being made to extend this system with another S, i.e. safety, viewed as safe and healthy working conditions. As a consequence, many researchers have proposed the concept of $5 \mathrm{~S}+1$ and even 6S. This approach is noticed in the publications of Gajdzik (2013), Junewick (2002) and Becker (2001).

The 5S practices, as argued by Zimon (2012), have an especially positive effect on the physical working conditions, thus offering opportunities to minimize the costs of reorganization at workstations. In the book by Karaszewski (2009), the reference to $5 \mathrm{~S}$ requires a consideration of:

- Seiri, as sorting and eliminating what's unnecessary,

- Seiton, as an expression of systematization, setting in order and segregation,

- Seiso, as sweeping and cleaning category,

- Seiketsu, which favours standardization and thus order,

- Shitsuke, relating to self-discipline.

As a consequence of using $5 \mathrm{~S}$ practices, safe working conditions result directly from the essence of the discussed system. This system somehow enforces the respect of legal regulations in the field of occupational safety and health, but it also determines internal guidelines concerning desirable behaviours and activities at workstations, this is important in terms of providing employees with safe and healthy working conditions. Szatkowski (2014) states that 'A good organization in and around your own workplace', which is the term used to define the $5 \mathrm{~S}$ system, also means a management that is safe for human, taking into account meeting human interests.

The analysis of the Polish literature reveals a peculiar manifestation of enthusiasm and an uncritical approach to LM and the consequences of using its tools, including the perspective of shaping safety of working conditions. If one looks critically at the objectives and tasks of LM, it can be observed without much insight that the dominant objective of LM is to improve the efficiency of production only, and ultimately its effectiveness. Humans are reduced to the role of a 'bio-robot', whose goal is to achieve the highest efficiency while self-limiting unnecessary downtime 
or excessive movements. Limiting downtime may mean increased time pressure, increased speed of performing activities and reduced micro-rest. Timing and layouts are often defined in the light of performance radicalization, forcing an increase in work intensity, and inappropriate, painful and tedious postures or increasing the risk of injuries and accidents caused by physical fatigue or fatigue related to the lack of concentration caused by mental fatigue. It cannot and must not be denied that many LM solutions, such as 5S, allow for the improvement in material conditions and safety at work. However, research on the impact of working conditions on mental health and psychosomatic health is now becoming the subject of more frequent explorations. Science has not developed any certainties and paradigms in this area yet.

A study by Valeyre (2007) indicates the negative aspects of implementing LM tools on employees' health and lives. In the United States, the degradation of workers' health resulting from the change of production organization to the LM concept lasted from the mid-1980s to the mid1990s. This is confirmed by research conducted by Askenazy (2001), Brenner et al. (2001), Fairris and Brenner (2001) and others. Research conducted by DaubasLetourneux and Thébaud-Mony (2001, 2003), Datta Gupta and Kristensen (2008) Asekenazy and Caroli $(2003,2010)$ and Bertrand and Stimec (2011) revealed that this phenomenon reached Europe in the 1990s. In the United States, numbers of accidents at work and occupational diseases began to decline in the mid-1990s. Askenazy (2006) states that one of the main reasons for this change is the role of the organization responsible for occupational safety and health (OSHA), which has been reinforced. Another equally important reason for this change is the growing use of the CSR concept by enterprises. A meta-analysis carried out by Orlitzky, Schmidt and Rynes (2003) reveals that CSR not only maintains the mental and physical health of employees by implementing better practices, but it has also been identified as a means to improve corporate financial results. Studies by Askenazy and Caroli (2003, 2010), Stock et al (2006) and Gollac (2005) have identified correlations between several main factors of working conditions that have led to the deterioration of the health status of employees. These factors included:

- Repetitive work, its intensity,

- Teamwork, the pace of work depends on the work of colleagues and machines,

- Rotating schedules,

- Compliance with quality standards and sitting position.

In conclusion of the theoretical considerations and achievements of the researchers in this area, it should be noted that the LM concept, in its basic version, was essentially oriented towards production efficiency and, in particular, towards machine efficiency. Man ceased to be the focal point of this concept. The links between the implementation of $5 \mathrm{~S}$ and its results in the area of shaping safety of working conditions in the selected enterprises became an inspiration for the analysis.

\section{Research Methodology}

The literature review indicates a cognitive gap in the relationships between physical and non-physical working conditions in the broad sense of the term, and the way $5 \mathrm{~S}$ practices are implemented.

Four research questions were asked in the study. Two questions concerned the direct relationship between the implementation of LM elements and the safety of working conditions. The first question was: Were the widely understood working conditions taken into account when implementing solutions of lean manufacturing in companies in Lower Silesia which implemented at least LM elements? The second question was: Were the effects on the physical and mental health of the workers before and after the implementation of lean methods studied? The next two questions concerned the stimulating role of $5 \mathrm{~S}$ practices on employees' creativity and making the scope 
of $5 \mathrm{~S}$ implementation dependent on the nature of the workplace.

The next part was based on the empirical material related to lean management (LM) implementations collected in three manufacturing companies in Lower Silesia which implemented LM in the form of $5 \mathrm{~S}$ practices in 2017-2018.

Given the qualitative nature of the problems discussed, the case study method was chosen to present them, with a greater focus on their in-depth understanding. Wójcik (2013) claims that this was aimed to find what can only be suggested by qualitative results.

Data sources concerned the analysis of documents concerning the implementation of the $5 \mathrm{~S}$ system in three manufacturing enterprises. These implementations were made in 2017-2018. Participants' observation and free-form interviews with managers and employees involved in the implementation of the system were also used. More specifically, an in-depth interview (IDI) was conducted, which is the direct method of the primary survey, with the respondent being an active object of the measurement, and the interviewees being in direct contact with the interviewers (conversation). In detail, the interview was conducted in accordance with the principles proposed by Kaczmarczyk (1999). The analysis was conducted using a descriptive method. The main objective of the study was to determine whether the implementation of the LM concept has taken into account the consequences of its implementation on the physical and mental health of the employees. In the enterprises surveyed, the $5 \mathrm{~S}$ method was the basic tool to reduce waste. This method was used first. Other LM methods have not been implemented yet.

\section{Results. Analysis of the effects of $5 S$ implementations on Safety of Working Conditions}

\section{The first of the $5 S$ Implementations Tested}

The implementation of the $5 \mathrm{~S}$ system began with identifying problems. This allowed to obtain information enabling to identify irregularities and shortcomings in the company.

The first problem identified is the lack of order in the offices. There were many papers and binders, and loose materials such as pens, staplers and briefcases. These things were not needed during work and generated excess clutter. In addition, there was no space for clothes and umbrellas. There were things for different purposes in the office. For example, empty boxes that serve as chairs. There was also no properly functioning information board. Another problem was the objects placed in the corridor between the office rooms and the production hall. Also, there were various items needed for production, but they hindered the movement of the employees. There was a mess at the production site. After use, the tools are put back in different places. If someone wants to use them again, he has to search for them or ask other colleagues where to find them.

Another weak point is the clutter on the shelves in the production hall. Many shelves are in the right places, but the problem is in what is placed on them. There are all kinds of tools, resources and personal protective equipment used for work. However, they are randomly distributed and mislabelled. Personal protective equipment is in one box, so if you want to find safety glasses, you must search the box because the glasses are mixed with gloves or earplugs that are used to protect against noise. The same applies to measuring instruments. They are currently stored in one container, but accessing it is difficult.

Another area that can cause confusion in a company is unordered documents. They mainly contain information about what range is currently in production and what activities have been carried out so far. It is important that all materials are arranged and always in place. Thanks to this, every employee starting a change can easily analyze the situation in the production process. This will avoid wasting time 
looking for necessary information and reduce production errors (reduction of losses). Another shortcoming was observed in employees' uniforms. Employees do not wear appropriate work clothing. Clothing should provide quick access to small but necessary tools. This means that an employee who needs to cut the film covering the box must either carry a knife in his pockets or waste time going to the shelf to bring the right equipment. Information boards are another area to look out for. It has been observed that sheets of paper are mostly torn off the wall, making it difficult to read the information written on them. The observation also shows that employees have no room to write down their own notes. The information is saved on colored random sheets of paper. It is noticeable that pens and markers also do not have their permanent location.

During the observation of the work flow, a general mess was also noticed, which was attempted to be cleaned up after the end of the shift. Workers have to waste time putting things back, while they could have done that earlier. Things which should not be present in the company were also observed. They only wasted space.

The 5S method was implemented with the support of: red and green cards, shadow boards, sets of coloured notes, plastic boxes with ready labels to write down on, information boards, posters and $5 \mathrm{~S}$ instructions, several binders and folders. The necessary cleaning equipment and new working clothing with pockets were used. The employees were given new work clothes that have pockets for small, most needed tools such as gloves, knives or protective earplugs.

At first, a selection was made, all employees working in the Production, Laboratory and Office Departments marked items with red and green labels. Next, all photographed their workstations and placed objects with red cards in appropriate places. Office workers tidied up their workstations by arranging all materials in a logical and orderly way using binders, folders, etc. Another step of the $5 \mathrm{~S}$ implementation is systematization. The tools in the workstations were arranged. One shadow board was placed to contain the most commonly used objects and the second was used to contain the daily cleaning equipment. The shelves were tidied up and clearly marked boxes were introduced, in which objects were segregated according to their purpose. In the production hall, auxiliary lines were painted. This helps employees find the place where to put the forklift, where to put the pallets and where to put the dirty or washed boxes. Information boards with production schedule and employees work schedule were introduced. Standardization was also implemented in the development of documents which would enable all procedures to be regulated. The collected photographs were printed and attached to the rest of the documents and instructions. The employee responsible for the implementation of lean management developed instructions on how to avoid mess, how to perform the cleaning work, which methods to use for control and motivation and how to build $5 \mathrm{~S}$ checklists. Self-discipline will be implemented including continuous improvement of cleaning methods, caring for the order in the workplace and following the principles of the $5 \mathrm{~S}$ method.

\section{The second of the examined $5 S$ implementations}

In the case of the second enterprise, the scope of implementation of LM methods was greater. The reason for implementing the philosophy and tools of LM in the company was the low productivity of the production process. Despite the introduction of new more productive injection machines, the company did not notice the expected results. Thus, the main goal of LM implementation was to improve performance. One of the proposed and implemented tools was the $5 \mathrm{~S}$ practice.

First, extensive research was conducted into the causes of performance degradation using the Ishikawa diagram. This analysis showed that one of the reasons for reduced productivity is the waste of time by employees. The source of this state of 
affairs is, among others, the need to search for: tools, personal protective equipment and documentation. Another reason for wasting time is the need to avoid unnecessary things that are in the production hall (extended time for completing internal logistics tasks).

This condition is caused by:

- Disorder at workplaces,

- No systematic cleaning of the hall,

- No designated places for products in the hall,

- No designated transport routes.

In practice, this problem requires the $5 \mathrm{~S}$ practice.

The most conspicuous mistake of the described company was the disorder prevailing in the workplace. To solve this problem, the $5 \mathrm{~S}$ tool had to be used. Its operation should cover the area of the production hall, social rooms, warehouses and the manager's office. Implementation should start with the manager's workplace as an example for the rest of the employees. As a first step, a Selection should exclude all unnecessary elements in the hall. These will include rubbish and packaging from used materials. This process should take about 30 days. The cleaned place will be ready to start the next step.

When introducing Systematization, specify the place in the hall for each material, semi-finished products, etc. The most important elements are cardboard boxes for finished products and already packed ones. The average number of cartons ready for finished products is 20 for each packing station. Cartons must be close to the tables so as not to take up space for passage. The place for the pallet of ready-to-transport products should contain only one of them so that they do not take up more space during production. Each ready pallet should be transported to the second room for loading. Each of these places should be clearly described with a maximum number of pieces marked. The same process must go through the warehouse to help determine the location of individual products. During cleaning, the items in the warehouse should be accurately recalculated and written down to create an inventory and later introduce kanban. Tools should have appropriate shelves, which, thanks to various types of hooks, can have their places marked. The shelves should be signed so as to know what objects should be in which place and what is currently in use. The shelves must be hung directly next to the machines to know which tools are needed during a failure, for example. The more they are, the easier it is to shorten the time during changeovers and reduce the time spent searching for parts. Elements needed for packaging, i.e. a label stuck on a cardboard box, a glue and an adhesive tape should also be at the packaging table. All personal belongings of employees should be placed in the cloakroom in previously purchased employees' lockers.

Seiso should include the introduction of cleaning schedules for the production hall. It should be divided into changes and areas due to the very large area of the hall. In this way, it becomes easier to take care of the systematic order.

In order to facilitate the maintenance of order in workplaces, Standardization must be introduced. It can be in the form of cards hung next to the workplaces as reminders of OHS rules, reminders to leave the workplace after cleaning it and reminders to hang tools in their places. In addition, cleaning reports must be included, in which employees must sign the current date of their work. It is important that in the first weeks, the introduced change is controlled by the manager.

Self-discipline ends the $5 \mathrm{~S}$. This is a process through which every employee goes alone. Instilled rules must be reproduced every day so that they later become a routine.

Properly introduced, the $5 \mathrm{~S}$ can handle SM's problems such as the clutter in the hall, the lack of space to go, the loss of time spent searching for tools and the lack of regularity in maintaining order. 


\section{The third of the examined $5 S$ implementations}

The 5S standards were introduced at the very beginning of its operation. They are the foundation for creating a work environment conducive to activities focusing on quality, harmonious work and continuous improvement of both human relations and production processes.

The 5S implementation program has already been completed and the compliance with the methodology is monitored on an ongoing basis. The $5 \mathrm{~S}$ assumptions are present on every production line, at every workplace and practically throughout the entire factory area.

Training is the first step in implementing the 5S method in this company. The trainings were twofold, one of them was for the management, the others were intended to train employees directly related to the production process, as well as office employees. In order to constantly motivate and support production employees, a team of 5S leaders, who were project coordinators, was selected for each department.

Subsequently, after reviewing the positions, it was found that the tools did not have designated storage locations. In the hall, there were pallets with lamination and cardboard boxes in dangerous places, distant from the workplace. The cleaning tools did not have a designated location and were put in random places after use.

Systematics is the next step. It is mainly the optimal placement of pallets with materials awaiting the next production order. Pallets with unused materials were directed back to the warehouse, as well as places for waste containers, work tools and documents were dealt with.

For this purpose, a number of visual solutions were used, which greatly facilitate the location and the storage of work tools and the cleaning agents or materials needed for the process by an employee, which allow to control their current location and condition. Solutions such as separating lines, colors, cabinets for storing cleaning agents and shadow boards were used. Permanent storage locations and the optimal number of pallet spaces with materials, and semi-finished products needed for process entry and exit have been determined using separating lines.

Separation lines have been divided into groups by their color. Knowing the meaning of individual colors allows you to eliminate a significant number of mistakes of employees working in the production process, and also significantly speeds up and facilitates the work of an employee. After the systematization of workplaces, standard cleaning procedures and criteria checklists were prepared. The checklist was made for items that require cleaning and the methods of cleaning them. Appropriate means were provided in the previously mentioned closet with cleaning agents. Cleaning standards prepared in this way are visible in every workplace and in every production line. The standards contain information on the method, measures and optimal duration of a given cleaning activity, and indicate the contractor for the given activity. Appointed $5 S$ team leaders regularly check the condition of equipment and positions. To reach that end, they use a checklist of cleaning agents to support inspection. Maintaining the area in a good condition by proper cleaning of the station and its maintenance allows the identification of potential sources and causes of pollution, waste and leaks.

When the employees have already obtained the appropriate knowledge in the field of maintaining cleanliness in their positions, the next step, which is $4 \mathrm{~S}$ Standardization, has been implemented. Standards have been set for steps 1S-3S to maintain what has been achieved so far. Visual standards that are clear and transparent to everyone have proved to be the best. Each shadow table is assigned to one production line.

The company also has a standardized approach to measuring the $5 \mathrm{~S}$ condition. This means the functioning of the 
scoreboard for each area and the cleaning schedule. In addition, the company introduced a standard of 5 minutes cleaning at the end of the shift.

The last step during the implementation of $5 \mathrm{~S}$ in the surveyed company was SelfDiscipline, which continues to date, because the authors of this paper are associated with the continuous work on changing habits in the way employees work. The selected $5 \mathrm{~S}$ leaders, determined in the schedule, carry out the so-called $5 \mathrm{~S}$ audits from time to time to check at which level are they and whether there are any deviations in the functioning of the workplaces from the established standards and to determine the necessary corrective actions, in terms of non-compliance, i.e. coaching (individual training) of an employee who does not comply with the $5 \mathrm{~S}$ rules. The audit is carried out according to an appropriately prepared audit card. The results of the audits carried out are then presented for a general review of the socalled 5S report table. It shows results, goals, current status, before and after photos, and a systematically refreshed bar chart showing the positive impact of the compliance with the $5 \mathrm{~S}$ rules on the functioning of the company.

The entire process of implementing the $5 \mathrm{~S}$ system in the company was a lengthy process and required and still requires very high commitment from all employees of the organization.

\section{Conclusions}

The analysis presented in this paper allowed the conclusion of taking into account the shaping of working conditions while designing and implementing LM solutions in light of ensuring employees health in physical and mental terms. The implementation of the $5 \mathrm{~S}$ practice did not significantly differ in the surveyed entities. The market in which they operate is stable and competitive. The work organization in the enterprises consists of a division of duties, in which specific tasks are assigned to employees and in specific areas.
As a result of the research, it was found that most of the activities were aimed at improving efficiency by reducing time loss. In response to the question whether the working conditions were taken into account during the implementation of the $5 \mathrm{~S}$, the results of interviews and document analysis indicate that working conditions have not been indicated as the purpose of implementing this method. Also, it was not ensured that work did not lead to negative changes in the employee's mental health.

The implementation works were not supervised by an OHS expert.

It can be concluded that the physical working conditions have been inadvertently improved by removing unnecessary items and creating places for individual materials, tools and devices.

In two cases, the actions were identified to improve the safety of working conditions. In the first case, it concerns changing, applying and controlling protective clothing as well as the use of other personal protective equipment. In the second case, the necessity to place OHS instructions, included in the $5 \mathrm{~S}$ rules, was indicated.

The interviews show that the places for specific items were not always correctly indicated. While obtaining the effect of standardization and systematization, ergonomics and process optimization resulting, the implementations did not validate the results of the implementation in terms of the effect of the changes on the employees' health, their well-being at work or the level of stress they experienced.

The study found that with the implementation of the $5 \mathrm{~S}$ principles, the employees felt: fear that they will not be able to cope with the new requirements; fear that they will not adapt to the new order, fear that they will have to look for something for a longer time, with the current state considered good; fear that the cleaning process will take additional time and they will not perform their basic assignments; fear that the cleaning will have to be carried out after the working time as agreed with the employer (without 
appropriate overtime) and fear that the working environment will start to resemble a sterile laboratory.

Another effect of standardization and systematization is that the workplace was depersonalized, which means the following for the employee and the employer:

- Easier preparation of a new employee for the position, shortening the training time to achieve the level of the expected efficiency,

- Maladjustment of the workplace to the physical characteristics of individual people. For people with physical parameters who are not adapted to the standard, it is possible to work only in a burdensome position, which can lead to a deterioration of the state of health of the musculoskeletal system, which should also be understood as a kind of exclusion,

- Exclusion of people with reduced mobility from work,

- Inspiring a sense of substitutability among employees, which leads to a reduction in their motivation and selfesteem,

- Fear for losing the job.

Interviews showed that the feeling of anxiety did not disappear but it was replaced by a habit that weakened its effect. The $5 \mathrm{~S}$ method is considered an important component of the lean management approach. It was implemented in a way that raised a lot of concerns among the employees. The health and mental well-being of the employees were not taken into account during the implementation of the 5S.

\section{Summary}

The results of the study encourage the development of such solutions in the $5 \mathrm{~S}$ system that will simultaneously ensure:

- Improving production efficiency;

- Safety and maintaining health at work (physical and mental health),

- The level of workplace organization that guarantees a certain level of personalization,
- Alleviating negative emotions in the process of implementing new management methods.

This solution can be offered by adapting the $5 \mathrm{~S}$ rules to individual employees. One could say that this would mean the development of the $5 \mathrm{~S}+\mathrm{P}$ concept. Moreover, many negative emotions and behaviors can be avoided by showing all employees a broader vision of the production system and the place of individual employees. In the case of planned reductions in employment, indicate the ways to support employees in obtaining new jobs or raising their competences. Detailed LM methods should be introduced only after ensuring an appropriate level of knowledge and a sense of security for the employees.

An important problem in conducting further research is the distinction between physical and non-physical factors shaping working conditions in the light of their impact on the physical and mental health. There may be physical conditions that affect mental health, but there may also be non-physical conditions that affect physical health. The question is also whether health should be considered psychosomatic so that conditions can have a greater impact on physical or mental health. Currently, the labor market is changing and more work is done in the service sector, where work conditions and health problems shift the focus from physical working conditions to non-physical and from physical health to mental, or at least psychosomatic health.

\section{Acknowledgment}

"The project is financed by the Ministry of Science and Higher Education in Poland under the programme "Regional Initiative of Excellence" 2019 - 2022 project number 015/RID/2018/19 with a total funding amount 10721 040,00 PLN" 


\section{References}

- Askenazy, P. (2001) 'Innovative workplace practices and occupational injuries and illnesses in the United States,' Economic and Industrial Democracy, 22(4), 485-516.

- Askenazy, P. and Caroli, E. (2003) 'Pratiquesinnovantes, accidents du travail et charge mentale :résultats de l'enquêtefrançaise. Conditions de travail 1998,' Perspectives interdisciplinaires sur le travail et la santé, 5(1).

- Askenazy, P. (2006) 'La santé et la sécurité dans les entreprisesaméricaines,' Actes de la recherche en sciences sociale, 163, 7289.

- Askenazy, P. and Caroli E. (2010) 'Innovative work practices, information technologies and working conditions: Evidence for France,' Industrial Relations 49(4), 544-65.

- Becker, J.E. (2001) 'Implementing 5S to promote safety and housekeeping,' Professional Safety, 46(8), 29-31.

- Bertrand, T. and Stimec, A. (2011) 'Santé au travail,' Revue Française de Gestion (214), 127-144.

- Brenner, M., Fairris, D. and Ruser, J. (2001) 'Flexible work practices and occupational safety and health: exploring the relationship between cumulative trauma disorders and workplace transformation,' Social Science Research Network. ID 333762 SSRN Scholarly Paper.

- Cierniak-Emerych, A. (2005) Europejskie standardy praw człowieka i warunków pracy, Wyd. IB-iS, Wrocław.

- Cottini, E. and Lucifora, C. (2013) 'Mental health and working conditions in Europe,' Industrial and Labor Relations Review, 66(4), 958-88.

- Coupaud, M. (2017) 'Determinants of health at work in the EU15: elaboration of synthetic working conditions indicators and their impacts on physical and mental health of workers,' International Journal of Manpower, 38(1) ,DOI: 10.1108/IJM02-2016-0040.
- Cropanzano, R.M.M., (2005) 'Social Exchange Theory,' An Interdisciplinary Review Journal of Management, 31(6), 874-900.

- Daubas-Letourneux, V. and ThébaudMony, A. (2001) 'Blind spots in our knowledge of industrial accidents,' Travail et Emploi, (88), 2542.

- Daubas-Letourneux, V. and ThébaudMony, A. (2003) 'Organisation du travail et santé dans l'UnionEuropéenne,' Travail et Emploi, (96), 9-35.

- Datta Gupta, N. and Kristensen, N. (2008) 'Work environment satisfaction and employee health: panel evidence from Denmark, France and Spain, 1994-2001,' European Journal of Health Economy (9), 51-61.

- EUROFOUND (2019) 'Working conditions', https://www.eurofound.europa.eu/pl/ topic/working-conditions (Date accessed the site 04.03.2019).

- Fairris, D. and Brenner, M. (2001) 'Workplace transformation and the rise in cumulative trauma disorders: is there a connection?' Journal of labor research, 22(1) 15-28.

- Gajdzik, B. (2013) 'Word Class Manufacturing in metallurgical enterprise,' Metalurgija 52(1).

- Gapp, R., Fisher, R. and Kobayashi, K. (2008) 'Implementing 5S within a Japanese context: an integrated management system,' Management Decision,4(4).

- Gollac, M. (2005) 'L'intensité du travail,' Revue économique, 56(2), 195216.

- Junewick, M. A. (2002) Lean Speak: The Productivity Business Improvement Dictionary, CRC Press: Taylor and Francis Group, New York.

- Kaczmarczyk, S. (1999), Badania marketingowe. Metody i techniki, PWE, Warszawa.

- Karasek, R.A. (1979)'Job demands, job decision latitude, and mental strain: implications for job redesign,'Administrative Science Quarterly, 24(2), 285-93.

- Karasek, R. and Theorell T. (1991) Healthy work: stress, productivity, and 
the reconstruction of working life, Basic Books, New York.

- Karaszewski, R. (2009) Nowoczesne koncepcje zarządzania jakością, Wyd. TNOiK. Stowarzyszenie Wyższej Użyteczności „Dom organizatora”, Toruń.

- Kornicki, L. and Kubik, Sz. (2008) Identyfikacja marnotrawstwa na hali produkcyjnej, ProdPress.com., Wrocław.

- Krot, K. and Lewicka, D., (2015) 'Wpływ jakości środowiska pracy na zachowania pracowników,' Zarzadzanie. Zeszyty Naukowe Uniwersytetu Szczecińskiego, Studia $i$ Prace Wydziału Nauk Ekonomicznych $i$ Zarzadzania,4(39), 95-109, DOI 10.15611/pn.2017.463.25.

- Sirven, N., Cardebat, J.M. and Coupaud M. (2015) 'Working conditions and the health of workers: An elaboration of a responsible prevention ratio,' Economic and Industrial Democracy, 38(4).

DOI:10.1177/0143831X15584084.

- Orlitzky, M., Schmidt, F. and Rynes, S. (2003) 'Corporate Social and Financial Performance: A Meta-Analysis,' Organization Studies,(24),DOI: 10.1177/0170840603024003910.

- Sperandio, J.C. (1980) La psychologie en ergonomie, Presse Universitaire de France,Paris.
- $\quad$ Stock, S., Messing, K., Tissot, F., Seifert, A.M. and Vézina, N. (2006) 'Les troubles musculo-squelettiques, la détressepsychologique et les conditions de travail au Québec: relations complexes dans un monde du travail enmutation,' Santé Société et Solidarité, 5(2), 45-58.

- Szatkowski, K. (2014) Nowoczesne zarządzanie produkcją. Ujęcie procesowe, Wydawnictwo PWN, Warszawa.

- Valeyre, A. (2007) 'Les conditions de travail des salariés dans l'Unioneuropéenne à quinzeselon les formesd'organisation EU-15',Travail et Emploi, (112)/11-12, 35-47, posted on 05 November 2010, consulted on 21 December 2018

http://journals.openedition.org/travail emploi/2185; DOI: 10.4000/travailemploi.2185 .

- Walentynowicz, P. (2013) Uwarunkowania skuteczności wdrażania Lean Management w przedsiębiorstwach produkcyjnych $\mathrm{w}$ Polsce, Wydawnictwo Uniwersytetu Gdańskiego, Gdańsk.

- Wójcik, P. (2013) 'Znaczenie studium przypadku jako metody badawczej w naukach o zarządzaniu', e-Mentor, 48(1). 17-22.

- Zimon, D. (2012) 'Rola jakości w logistyce produkcji', PiZ T.13(12). 